tigation; in one paper enumerating no less than fifteen conditions in which it was indicated, including hydronephrosis, pyelitis, pyonephrosis and renal tubereulosis. ${ }^{2}$

In his papers for 1913, some modification of his former teachings is found, in that he states that it is contra-indicated in large hydronephroses, and in any case in which the pelvis cannot readily drain itself of the injected solution; that in malignant renal tumors it should not be used except when other means of diagnosis fail to identify the tumor ${ }^{14}$ that in his experience, severe reactions following pyelography have been due either to errors in technic or to lack of care in the selection of cases; and that pyelography should not be employed unless the existence or nature of a lesion in the urinary tract cannot be diagnosed in any other way.

To lessen the danger of overdistention, the gravity method of Thomas, or the still more accurate method of Tennant, who used a mercury manometer for estimating pressure, should be used. Even then the danger is not eliminated, for as yet we have no method of estimating the amount of pressure that may be safely used in

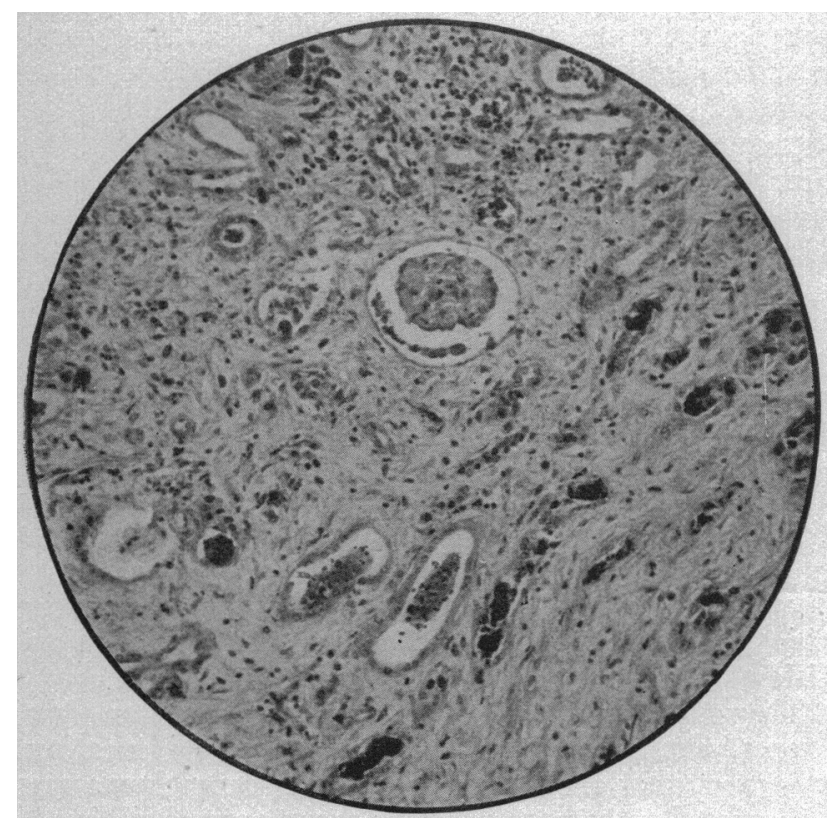

Fig. 9.-Section from Prof. Mallory's case; collargol in tubules and inside the capsule of a glomerulus; $\times 110$.

any given case; and, as this must vary in every case, a standard for comparison must be very difficult to establish.

The cases here presented prove that solutions injected into the kidney pelvis may, under circumstances which are not entirely under our control, ascend into the tubules and out into the surrounding kidney tissue carrying with them such infectious material as may be present in the pelvis and set up serious inflammatory lesions. With this clearly established, it would seem that injections are contra-indicated in the presence of infection in the kidney or kidney pelvis, and in cases in which the integrity of the kidney has been impaired by injury or disease.

14. Braasch Willium F.: Clinical Data on Malignant Renal Tumors, THE JoulsaL A. M. A., Jan. 25, 1913, p. 274.

Style.-Nothing is easier than to write so that no one can understand; just as, contrarily, nothing is more difficult than to express deep things in such a way that every one must necessarily grasp them.-Schopenhauer.

\section{RADIUM IN THE TREATMENT OF BLASTOMYCOSIS}

WITH REPORT OF A CASE

\section{FRANK EDWARD SIMPSON, M.D. \\ CHICAGO}

In a previous article ${ }^{1}$ the case now reported more fully was briefly referred to.

So far as I can learn, radium has not been used hitherto in the treatment of blastomycosis. A priori it

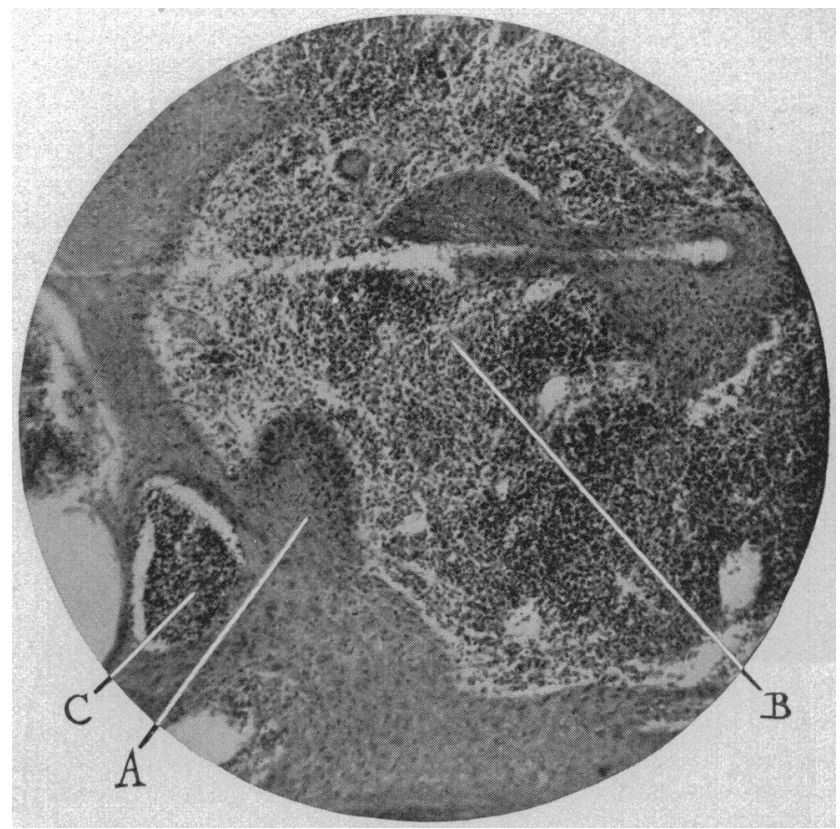

IIg. 1.-Transverse section showing proliferated epithelial lavers $(A)$ and on large $(B)$ and one small $(C)$ abscess; $X 90$.

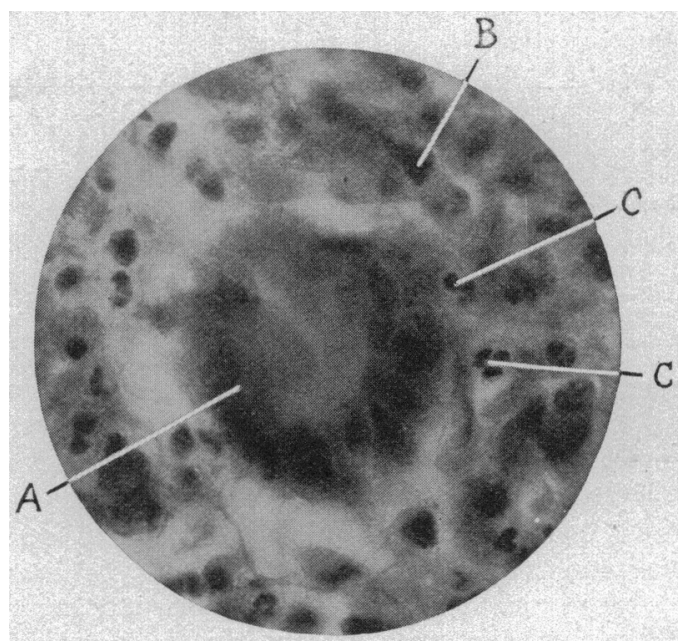

Fig. 2.-From same section. Multinuclear giant-cell (A) surrounded by epithelial cells $(B)$ and polynuclear leukocytes $(C)$; oil immersion; $\times 650$.

xas expected that radium would be effectual in this disease, and the opportunity of treating a case presented itself in May, 1913.

History.-The patient, a man, aged 24, came under observation at the Chicaro Policlinic Hospital with a lesion at the inner canthus of the left eye. The lesion, which was of three months' duration, involved the upper and the lower lid and covered an area of about $2 \mathrm{sq} . \mathrm{cm}$. (Fig. 3 ). It was of

1. Simpson, Frank E.: Radium in Skin Discases, The Jourxal A. 2. A., July 12, 1913, p. so. 
verrucous aspect, but at the periphery an inflammatory border $1 / 8$ inch wide was present containing a few abscesses the size of pin-points. Pus could easily be squeezed from between the papillae of the patch. The clinical diagnosis of blastomycosis was made. In a smear from the peripheral abscesses, Dr. J. S. Lindholm demonstrated the blastomyces. The patient had previously sought treatment from several oculists in another city and had refused excision, which had been advised.

Treatment.-Radium treatment was tentatively advised. A radium varnish applicator, one-quarter strength, containing $0.04 \mathrm{gm}$. of radium-barium salt was easily applied. An exposure of three hours was given in fractional doses in the course of three weeks. A slight inflammatory reaction ensued. This caused no pain and was followed by the complete disappearance of the lesion. A few weeks later two minute points at the extremities of the lesion on the upper and lower lids were noted by the patient. An exposure of fifteen minutes was given to each place with complete recovery (Fig. 4), which has been maintained to the present time.

Result.-The beauty of the cosmetic result cannot, I believe, be exceeded by any other method. Not the slightest tendency to ectropion can be observed, and the site of the lesion is almost imperceptible. When the patient was first seen a small piece of tissue was removed from the lower part of the lesion for microscopic examination. Dr. Maximilian Herzog kindly examined the sections, and I am greatly indebted to him for the following report:

Microscopic Report.-A small piece of tissue was fixed in Zenker's solution, subsequently embedded in paraffin, sectioned and stained. The microscopic examination failed to show the characteristic doublecontoured, budding blastomyces, but the histologic structure found was that seen in typical blastomycotic dermatitis. The sections show the following:

The epithelial layers are very much thickened and the epithelial masses here and there rise in irregular projections. The inter-

papillary eptithelial pegs, widened and much elongated, pro ject deeply downward. The proliferated epithelial masses are riddled with small abscesses, varying from microscopic to pin-head size (Fig. 1); hence some of them clearly can be seen with the naked eye in the sections. Loosely attached to the outermost epithelial cells are completely or partially desquamated horny scales. There is no clearly recognizable stratum lucidum, but the epithelial cells next to the horny layer show a rather excessive amount of granular keratohyalin. The epithelia next to the stratum granulosum are quite normal in character with well-defined intercellular prickles; the nuclei are normal in appearance; karyokinetic figures here and there are seen. The cells situated in the older layers of the elongated and widened interpapillary pegs are somewhat degenerated; the prickles are not distinct; the nuclei are shrunken and situated in a vacuolated cell protoplasm. Migrated polynuclear leukocytes are found between the epithelial cells.

Some of the larger abscesses have broken toward the surface, but they are still partially covered by desquamated horny scales: The smaller abscesses are completely surrounded by epithelial layers. The abscesses contain numerous densely crowded polvnuclear leukocytes, mostly of the neutrophil variety, few eosinophilic cells only, red blood-corpuscles and epithelioid cells, the latter evidently derived from fixed connective-tissue cells, and occasionally a multinuclear giant. cell (Fig. 2). A remnant of a vessel also was seen here and there, showing that the abscesses are primarily developed in connective tissue (papillary layer) and only later on become surrounded by the proliferating epithelial cells. The papillae between the enlarged epithelial pegs and the cutis generally show an extensive inflammatory infiltration of both proliferated fixed connective-tissue and wandering leukocytic cells.

59 East Madison Street.

\section{MENTAL HEALING}

\section{AN ADMONITION}

J. VICTOR HABERMAN, A.B., M.D., D.M. (BERLIN)

Instructor in Neurology and Psychotherapy at the College of Physicians and Surgeons, Columbia University NEW YORE

We have all heard much within the last few years about psychopathology and psychotherapy. The very words, especially the latter, have crept into the daily press and thence into focal interest of the lay mind. Popular books have been published on the subject, and soon thereafter, garbled by dilettantes, sundry articles in monthly and weekly magazines. At the same time the stage took up the theme of all-influencing and influenceable mind. In consequence, the layman to-day is doubtless as well informed on the subject-most superficially of course - as the majority of physicians. Religious cultism with metaphysical offshoots, new thoughtists, chiropractics, etc., have sprouted like mushrooms over night. These "schools" have overrun the land and with undaunted persistence have spread and fastened their propagandas until they stand firmly as monuments of shame to the poor belated imagination and poorer insight into human nature of the very men who should be trained to know men best. The secessionists to these ultraschools run up to vast thousands-and no sooner do they enter than they themselves become charged with proselytism and prove an attracting source on every side.

It has taken long for the physician to recognize this; he grasps it but vaguely now-or he would stand aghast. Countless times has he read of the power of mind over body and functions-but all the while kept his myopic eyes just on disease-disease, the cause of which was assiduouslv assayed and treated with scarcely a thought of the patient who stood beside. But disease does not always respond to treatment, or only but slowly, or indeed but poorly in poor hands. Beside there are a host of morbid conditions which become protracted bv inviting attention on them. And sick mortals are impatient. In the meantime the afflicted have heard the eall "the doctors gave him up, but the 'healer' got. him well"; and with curiosity mixed with hope, infected with the suggestion inherent in the thing "yes, marbe it is so"-urged the trial, and expectant and attentive, saw the "miracle" come true.

Who doubts it for a moment? Who that knows but an iota of the psychologv of expectant attention will deny its plausibility, or can doubt it to be true! And who among us has not now heard of patients doing poorly in medical hands who prospered when they took up "Science"? Do not our own colleagues recommend "healers" for functional disease, for "imaginative troubles and things"? And who does not notice with alarm the rise of cult after cult, the glaring prosperity of these churches, the sprouting of proselytes in every town- 